Results Natural killer cell cytotoxicity, in the absence of IL-2 stimulation, was no different between the groups. With IL-2 stimulation, EU demonstrated significantly higher cytotoxicity compared to $\mathrm{cHCV}(32.8 \pm 4.4 \%$ vs $17.6 \pm 3.2 \%, \mathrm{p}=0.023)$, with similar levels to SR $(27.7 \pm 9.9 \%, p=0.50)$. The proportion of $\mathrm{NK}$ cells in PBMC was not significantly different between the groups. Conclusion The current findings point to enhanced NK cytotoxicity in EU cases compared to those with chronic infection and suggests a role for NK cells in early viral clearance and resistance to HCV infection.

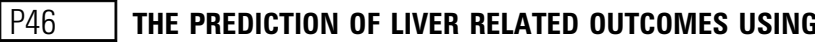 HISTOLOGICAL TOOLS AS AN ENDPOINT FOR STUDIES EVALUATING ANTI-FIBROTIC THERAPIES}

\author{
doi:10.1136/gutjnl-2011-300857a.46
}

${ }^{1} \mathrm{G}$ E Dolman, ${ }^{2} \mathrm{G}$ Li, ${ }^{3} \mathrm{G}$ Burgess, ${ }^{4} \mathrm{~T}$ Gray, ${ }^{4} \mathrm{~A} M$ Zaitoun, ${ }^{5} \mathrm{~W}$ Irving, ${ }^{1} \mathrm{I} N$ Guha. ${ }^{1}$ Nottingham Digestive Diseases Centre/Biomedical Research Unit, University of Nottingham; ${ }^{2}$ Pfizer Inc, China; ${ }^{3}$ Pfizer Ltd, UK; ${ }^{4}$ Department of Histopathology, Nottingham University Hospitals NHS Trust; ${ }^{5}$ Department of Microbiology, Nottingham University Hospitals NHS Trust

Introduction Liver related outcomes (LRO) represent a meaningful end-point for future anti-fibrotic therapies. Staging of liver fibrosis on histology is a surrogate for these outcomes but may not be an ideal tool.

Aim Our initial aim was to determine liver related outcomes and survival from the individual stages of significant fibrosis. Our second aim was to assess the value of morphometric collagen quantification within cirrhosis to predict clinical outcomes.

Method The study cohort was selected from a single centre within the Trent HCV study, a prospective cohort which began in 1991 to address the natural history of chronic hepatitis C. Inclusion criteria for this study were the presence of significant fibrosis (at least Ishak Stage (IS) three on biopsy) and at least 3-year follow-up post biopsy. LRO was defined as decompensation (variceal bleeding, ascites, encephalopathy), HCC, liver transplant and liver-related death. Automated morphometry was performed to measure the Collagen Area Fraction (CAF). Survival at 3, 5 and 7 years respectively was evaluated.

Results The study cohort comprised 155 patients $(70 \%$ male; mean age 49 years). The median follow-up time was 78 months. A LRO occurred in 48 patients (31.0\%, estimated annual incidence $5.2 \%$ ). HCC developed in 16 patients (10.6\%, estimated annual incidence $1.6 \%)$ liver-related death occurred in 34 patients $(21.9 \%$, estimated annual incidence $3.3 \%$ ); clinical decompensation developed in 20 patients (13.3\%, estimated annual incidence 2.1\%). See Abstract P46 table 1. CAF was measured in a subgroup of 89 patients. The median $\mathrm{CAF}$ was calculated for each Ishak stage and increased progressively towards the more advanced stages. (IS 3: median CAF 3.7\%, IOR 1.5-5.1; IS 4: median CAF 5.2\%, IOR 2.8-7.4; IS 5: median CAF 6.8\%, IOR 3.4-9.5; IS 6: median CAF 9.9\%, IOR 6.2-15.7). Within Ishak stage 6 the median CAF scores predicting LRO were higher (13.89,
12.48 and $12.69 \%$ ) compared to median CAF scores in patients with no outcomes $(8.59,8.32$ and $8.10 \%)$ at years 3,5 and 7 respectively.

Conclusion Clinical outcomes represent realistic and meaningful end-points for future trials evaluating anti-fibrotic agents once advanced fibrosis has developed. Further development and validation of morphometry within advanced fibrosis could enable better identification of patients at risk of more rapid progression of liver disease than Ishak stage alone.

\section{P47 DE-NOVO ANTIVIRAL THERAPY WITH NUCLEOS(T)IDE ANALOGUES IN 'REAL-LIFE' PATIENTS WITH CHRONIC HEPATITIS B INFECTION: COMPARISON OF VIROLOGICAL RESPONSES BETWEEN LAMIVUDINE + ADEFOVIR VS ENTECAVIR VS TENOFOVIR THERAPY}

doi:10.1136/gutjnl-2011-300857a.47

I Carey, H Nguyen DorothyJoe, M Al-Freah, S Knighton, M Bruce, A Suddle, P M Harrison, K Agarwal. Institute of Liver Studies, King's College Hospital NHS Foundation Trust

Introduction Several nucleos(t)ide analogues (NA) are approved for the treatment of chronic hepatitis $B(\mathrm{CH}-\mathrm{B})$; all aim to control HBV replication with minimal risk of drug-resistance and toxicity. Limited comparative data exist assessing differences between viral responses to different de-novo therapeutic regimens in real-life cohorts.

Aim To assess and compare virological and serological responses in 3 real-life $\mathrm{CH}-\mathrm{B}$ de-novo therapeutic cohorts-lamivudine $100 \mathrm{mg} / \mathrm{d}$ + adefovir $10 \mathrm{mg} / \mathrm{d}(\mathrm{LAM}+\mathrm{ADV})$ combination therapy vs entecavir $0.5 \mathrm{mg} / \mathrm{d}$ (ETV) vs tenofovir $245 \mathrm{mg} / \mathrm{d}$ (TDF) monotherapies.

Method Patients: NA therapy naive $406 \mathrm{CH}-\mathrm{B}$ patients treated at a single-centre practice [median 30 months (m), range 3-72] were split into three groups according therapy regimen: LAM+ADV ( $n=192,78 \%$ males, median age $40 y, 35 \% \mathrm{HBeAg}+, 34 \%$ cirrhosis, median duration 36 months), ETV ( $n=154,79 \%$ males, median age $42 \mathrm{y}, 31 \% \mathrm{HBeAg}+, 34 \%$ cirrhosis, median duration 28 months) and TDF ( $\mathrm{n}=60,50 \%$ males, median age $40 \mathrm{y}, 23 \% \mathrm{HBeAg}+, 25 \%$ cirrhosis, median duration 9 months). HBV DNA viral load tested by real-time PCR $[\log 10 \mathrm{IU} / \mathrm{ml}]$, serology for $\mathrm{HBeAg} / \mathrm{HBsAg}$ were compared between baseline, months 3, 6, 9 and 12. Five responses, evaluated by change in serum HBV DNA, were recorded: (1) complete (CR) $<12 \mathrm{IU} / \mathrm{ml}$; (2) partial (PR), fall $>3 \log 10$ but $>12 \mathrm{IU} / \mathrm{ml}$; (3) slow (SR), fall 2-3 log10; (4) non-response (NR), fall $<1 \log 10 ; 5)$ viral breakthrough $(\mathrm{VB})$, rise $>1 \log 10$ from nadir. HBV genotypic resistance was tested pre-treatment and at the time of SR, NR or VB by direct sequencing.

Results Baseline HBV DNA was similar in all cohorts (median $\log _{10}$ 4.6 vs 4.4 vs $4.2 \mathrm{IU} / \mathrm{ml}$ ), higher proportions achieved CR in TDF cohort than LAM+ADV and ETV (m3: $78 \%$ vs $48 \%$ and $53 \%$, $\mathrm{p}<0.01 ; \mathrm{m} 6: 82 \%$ vs $60 \%$ and $65 \%, \mathrm{p}=0.02 ; \mathrm{m} 9: 86 \%$ vs $62 \%$ and $55 \%, \mathrm{p}<0.01$ ), but were similar at $\mathrm{m} 12: 80 \%$ vs $73 \%$ and $76 \%$ and there were no differences in PR, SR and NR in all groups. HBV DNA

Abstract P46 Table 1 LRO and survival by Ishak Stage

\begin{tabular}{llllll}
\hline $\begin{array}{l}\text { Ishak } \\
\text { Stage }\end{array}$ & $\begin{array}{l}\text { Annual Incidence } \\
\text { of LRO (\%) }\end{array}$ & $\begin{array}{l}\text { HR of LRO } \\
\mathbf{( 9 5 \% ~ C l , ~ p ~ v a l u e ) ~}\end{array}$ & $\begin{array}{l}\mathbf{3} \text { year } \\
\text { survival (\%) }\end{array}$ & $\begin{array}{l}\mathbf{5} \text { years } \\
\text { survival (\%) }\end{array}$ & $\begin{array}{l}\mathbf{7} \text { years } \\
\text { survival (\%) }\end{array}$ \\
\hline 3 & $0.7 \%$ & Ref. & $97.7(84.6,99.7)$ & $97.7(84.6,99.7)$ & $94.1(77.6,98.5)$ \\
4 & $3.2 \%$ & $4.76(0.87$ to $26.016,0.0715)$ & $93.8(63.2,99.1)$ & $87.1(57.3,96.6)$ & $78.4(46.0,92.6)$ \\
5 & $5.1 \%$ & $6.996(1.578$ to $31.019,0.0105)$ & $94.4(79.6,98.6)$ & $82.8(65.6,91.9)$ & $68.2(48.6,81.7)$ \\
6 & $11.0 \%$ & $15.986(3.816$ to $66.961,0.0001)$ & $68.8(54.6,79.3)$ & $53.3(38.6,66.0)$ & $41.8(26.9,56.0)$ \\
\hline
\end{tabular}

